DOI: http://dx.doi.org/10.7867/1809-0354.2019v14n2s1p792-814

\title{
GÊNERO EM LIVROS DIDÁTICOS: ANÁLISE DE DOIS LIVROS DA EJA (LÍNGUA PORTUGUESA E LÍNGUAS ESTRANGEIRAS MODERNAS)
}

\section{GENDER IN TEXTBOOKS: ANALYSIS OF TWO EJA TEXTBOOKS (PORTUGUESE AND MODERN FOREIGN LANGUAGES)}

\section{GÉNERO EN LIBROS DIDÁCTICOS: ANÁLISIS DE DOS LIBROS DE LA EJA (LENGUA PORTUGUESA Y LENGUAS EXTRANJERAS MODERNAS)}

PINHEIRO, Renata Kabke rekabke@gmail.com UFPel - Universidade Federal de Pelotashttps://orcid.org/0000-0003-0066-0503

SILVA, Márcia Alves da profa.marciaalves@gmail.com UFPel - Universidade Federal de Pelotas https://orcid.org/0000-0002-4727-2623

RESUMO No Brasil, apesar de a docência ser exercida majoritariamente por mulheres, é possível perceber uma falta de conhecimento sobre os estudos feministas e de gênero. Isso pode ter reflexos em sala de aula, já que os livros didáticos muitas vezes trazem representações de gênero estereotípicas, podendo influenciar a construção da identidade das estudantes. Neste estudo, observamos como a mulher é representada e qual sua representatividade nas imagens dos livros de Língua Portuguesa e Língua Estrangeira selecionados pela rede municipal de ensino para a Educação de Jovens e Adultos na cidade de Pelotas. Nosso objetivo é fornecer um exemplo de como essa observação crítica pode ser feita pelas/os docentes e servir de base para um trabalho em sala de aula visando desconstruir as representações estereotípicas, a invisibilidade e o desprestígio da mulher.

Palavras-chave: EJA. Gênero. Imagens. Livros didáticos.

ABSTRACT Despite the fact that, in Brazil, teaching is a profession followed mostly by women, a lack of knowledge in feminist and gender studies among them is actually perceptible. This may have repercussions in the classroom, since textbooks often present stereotypical gender representations, which can influence on the construction of female students' identities. In this paper, we verify how women are portrayed and what their representativeness is in the images found in the Portuguese and Foreign Language textbooks chosen for Youth and Adult Education (in Portuguese, EJA) by the municipal school network of Pelotas. Our aim is to provide an example of how teachers can do this critical observation, as well as some basis for work in the classroom seeking to deconstruct stereotypical representations, the invisibility and discredit of women.

Keywords: EJA. Gender. Images. Textbooks. 
RESUMEN En Brasil, aunque la enseñanza es realizada principalmente por mujeres, es posible notar una falta de conocimiento sobre los estudios feministas y de género. Esto puede tener repercusiones en la clase, ya que los libros de texto a menudo tienen representaciones de género estereotípicas y pueden influir en la construcción de la identidad de las estudiantes. En este estudio obsevamos cómo está representada la mujer y cuál su representabilidad en las imágenes de los libros de Lengua Portuguesa y Lengua Extranjera seleccionados por el sistema educativo municipal para la Educación de Jóvenes y Adultos en la ciudad de Pelotas. Nuestro objectivo es proporcionar un ejemplo de cómo las/los profesoras/es pueden hacer esta observación crítica, y al mismo tiempo ser una base para el trabajo en el aula con la intención de deconstruir representaciones estereotípicas, la inv isibilidad y el descrédito de las mujeres.

PALABRAS CLAVE: EJA. Género. Imágenes. Libros didácticos.

\section{INTRODUÇÃo}

Ao longo de nossas pesquisas em educação percebemos uma carência de conhecimento sobre os estudos feministas e de gênero por parte de um grande número de docentes. Ao mesmo tempo, no Brasil a docência é uma profissão exercida majoritariamente por mulheres ${ }^{1}$, por isso acreditamos ser de extrema importância levar a professoras e professores reflexões sobre as representações de gênero - em especial da mulher - que livros didáticos trazem, já que, mesmo com os avanços da tecnologia, os livros ainda são uma importante ferramenta de trabalho na sala de aula.

Os livros didáticos destinados ao ensino fundamental regular têm sido foco de diversos estudos, porém pouca atenção tem sido dada aos utilizados nesse nível na Educação de Jovens e Adultos (EJA). Tal diferença é natural, dada a importância da escola na formação das crianças e de sua identidade enquanto pessoas, mas se considerarmos que o ser humano está em constante processo de (re)construção de si

\footnotetext{
1 Os dados mais recentes disponibilizados pelo MEC são do Censo do Professor de 2007 que diz que, dos 4.104.882 professores em atuação na Educação Básica, Educação Infantil, Ensino Fundamental, Ensino Médio e Educação Profissional, 3.330.887 são mulheres, ou seja, 81,14\%. Fonte: Ministério da Educação - Censo do Professor. Disponível em: <http://portal.mec.gov.br/plano-nacional-de-formacao-deprofessores/censo-do-professor>. Acesso em: 10 jul. 2017.
} 


\section{Atos de Pesquisa em Educação - ISSN 1809-0354 \\ Blumenau, v.14, n.2, supl.1, p.792-814, out./nov. 2019 \\ DOI: http://dx.doi.org/10.7867/1809-0354.2019v14n2s1p792-814}

mesmo e que a sociedade vive um momento em que a (re)afirmação de identidades de raça, etnia e gênero passou a ter uma significância considerável, observar os livros destinados a estudantes da EJA revela-se tanto pertinente quanto relevante.

Por essa razão, para este trabalho selecionamos dois livros, ainda em uso, do Plano Nacional do Livro Didático (PNLD) de 2014, e, dentre os pontos que podem ser analisados em livros didáticos para verificar representações de gênero (a saber: as imagens, os textos para leitura e as frases utilizadas como exemplo do conteúdo sendo trabalhado), escolhemos as imagens pelo fato de ser inegável a "predominância contemporânea de uma cultura visual" (PELLEGRINI, 2008, p.49). Além disso, por questões de limite de páginas, optamos por um foco específico dentro das questões de gênero: a mulher.

Neste estudo, então, verificamos como a mulher é representada e qual sua representatividade (em termos de frequência de aparição) nas imagens dos livros didáticos de Língua Portuguesa e Língua Estrangeira Moderna selecionados pela rede municipal de ensino público para a EJA em nossa cidade. Com base em nossa crença de que o conhecimento científico produzido nas universidades deve ser compartilhado e utilizado para a melhora da sociedade, o objetivo deste trabalho é fornecer a docentes em geral um exemplo de observação crítica de imagens em livros didáticos, demonstrando que ela pode ser feita por elas/es próprias/os e servir de base para um trabalho em sala de aula que busque desconstruir não só representações estereotípicas, mas também a invisibilidade e o desprestígio das mulheres que séculos de cultura androcêntrica perpetuaram e cristalizaram.

\section{SOBRE NOSSO OBJETO DE ESTUDO}

\subsection{GÊNERO, MULHERES E LIVROS DIDÁTICOS}

Apesar de algumas pessoas ainda confundirem um conceito com o outro, há algumas décadas já existe a compreensão de que gênero não é sinônimo de sexo biológico, mas uma construção histórica, social e cultural. Isso quer dizer que os membros 
da espécie humana são classificados em dois grupos diferenciados anatômica e fisiologicamente - o que resulta em um binarismo baseado no sexo da pessoa. Entretanto, as diferenças de comportamento que porventura possam existir entre indivíduos de sexos diferentes não são em absoluto determinadas biologicamente, e sim resultado de uma espécie de "aprendizado".

Nesse sentido, Joan Scott (1995) conceitua gênero como um construto social que, apoiado em condições biológicas (aparatos sexuais), determina que certos modos de agir e pensar são próprios de um homem ou próprios de uma mulher, sendo essa relação uma oposição binária (masculino/feminino) que gera uma relação de poder: a supremacia do masculino - e, consequentemente, da masculinidade - sobre o feminino/feminilidade em um determinado recorte temporal.

É do reconhecimento dessa diferença de tratamento e da necessidade de questioná-la que surgem os estudos de gênero, inicialmente dedicados à chamada "condição feminina", depois à "problemática da mulher" e, mais recentemente, ao "gênero", passando a englobar outras possibilidades além do binômio homem/mulher. No entanto, enquanto considerações sobre a condição feminina, tais estudos tinham o defeito de homogeneizar todas as mulheres, desconsiderando as diferenças de etnia, raça, idade e classe social, e demonstrando uma falta de articulação das diferentes esferas em que se dá a opressão sobre elas. Das limitações desse modo de ver os problemas relacionados à mulher é que surge o conceito de gênero enquanto categoria relacional, passando as diferenças entre os sexos e as relações decorrentes delas a serem observadas no campo do histórico, do social e do discursivo, para além da simples diferença anatômica. Dentro dessa concepção, gênero é "sobretudo uma categoria que serve para 'dar sentido' a esta diferença" (SCOTT, 1995, p.10).

Com a concepção de gênero como uma categoria sujeita à influência de outras, fica claro que ele não é algo que pode ser concretizado materialmente. Comportamentos tidos como femininos ou masculinos, por exemplo, são históricos, ou seja, não são estáveis ao longo do tempo. A partir dessa percepção, surge um novo conceito de gênero, para o qual é exatamente a repetição de atos e gestos, independentemente do sexo da pessoa, que de certa forma materializa o gênero. Nas palavras de Butler, gênero é 


\section{Atos de Pesquisa em Educação - ISSN 1809-0354
Blumenau, v.14, n.2, supl.1, p.792-814, out./nov. 2019 \\ DOI: http://dx.doi.org/10.7867/1809-0354.2019v14n2s1p792-814}

a estilização repetida do corpo, um conjunto de atos repetidos no interior de uma estrutura reguladora altamente rígida, a qual se cristaliza no tempo para produzir a aparência de uma substância, de uma classe natural de ser. (BUTLER, 2003, p. 59).

Dito de outra forma, segundo essa concepção o gênero é performativo, ou seja, algo que a pessoa realiza em suas interações com outros por meio da repetição de atos que ligam ou identificam a pessoa com o (tido como) masculino ou feminino. Ainda assim, é possível mesmo nos dias de hoje perceber a persistência tanto de uma binarização principalmente no que se refere às relações de poder e espaços sociais ocupados por homens e mulheres - como uma estabilidade de papéis falsamente natural e baseada na biologia.

No que se refere a livros didáticos e gênero - mais especificamente mulheres -, publicações mais recentes, preocupadas em ser "politicamente corretas", até se referem às conquistas femininas ou feministas, porém ao mesmo tempo reiteram papéis específicos de gênero. Jane Flax defende que devemos fazer um exame daquilo que significa o "feminino" e o "masculino" em uma determinada sociedade, sendo necessário que repensemos nossas concepções a fim de

[...] alcançar um distanciamento crítico em relação aos arranjos de gênero existentes. Esse distanciamento crítico pode ajudar a desobstruir um espaço no qual a reavaliação e a alteração dos nossos arranjos de gênero existentes se tornem mais possíveis. (FLAX, 1991, p. 219).

Concordamos com Flax que essa reavaliação é necessária - em nosso caso, principalmente no que se refere a livros didáticos - para que possamos desconstruir arranjos sociais androcêntricos cristalizados e estabelecer novas relações de gênero que sejam mais igualitárias e democráticas. A escola configura-se, então, como um local fundamental para que tal projeto se concretize, já que, como nos diz Bell Hooks, a sala de aula, mesmo "[...] com todas as suas limitações, continua sendo um ambiente de possibilidades". (HOOKS, 2013, p. 273). 
Atos de Pesquisa em Educação - ISSN 1809-0354

Blumenau, v.14, n.2, supl.1, p.792-814, out./nov. 2019

DOI: http://dx.doi.org/10.7867/1809-0354.2019v14n2s1p792-814

2.2 A ESCOLA E A CONSTRUÇÃO DA(S) IDENTIDADE(S)

Desde o lançamento dos Parâmetros Curriculares Nacionais (PCNs) em 1997, muitas reflexões têm sido feitas sobre as estratégias utilizadas em sala de aula para que as/os estudantes se mantenham em um constante processo de construção e reconstrução dos seus conhecimentos. Tal processo é essencial, pois irá se refletir na forma como nossas/os estudantes veem o mundo diante de si e como veem a si mesmas/os perante o mundo, ou, em outras palavras, na construção de sua identidade.

Bakhtin explica que "a consciência individual adquire forma e existência nos signos criados por um grupo organizado no curso de suas relações sociais". (BAKHTIN, 1988, p. 35). Em sala de aula, portanto, as/os estudantes constroem-se como sujeito constantemente, e o que acontece ali pode não só interferir na concepção do "eu" de cada uma/um, como também pode influenciar todos os membros que compõem uma sala de aula a terem a mesma percepção. Dessa forma, o que é apresentado pelo livro didático - e em especial o que se refere à mulher - terá influência nessas concepções, com consequências tanto imediatas quanto a longo prazo.

Em relação a isso, verifica-se que, ainda hoje, em muitos livros didáticos a mulher é representada majoritariamente como dedicada a tarefas do lar e/ou cuidando dos filhos. Se o livro é mais "moderno", ela trabalha fora, porém quase sempre é professora, enfermeira ou secretária, sendo as profissões de mais prestígio em geral representadas por homens. É sabido que, no caso de crianças, em um momento de formação de sua personalidade, tais imagens podem reforçar a baixa autoestima das meninas e se tornarem referenciais, porém o mesmo raciocínio pode ser estendido para as estudantes da EJA, no sentido de que sua autoestima também pode ser afetada por essas imagens, sua identidade enquanto ser humano que quer ser diferente do que está ali retratado pode ser abalada, e sua relação com outras pessoas - principalmente quando estão em jogo relações de poder baseadas em gênero - pode ser influenciada por falsas ideias de superioridade masculina. No caso dos estudantes (homens), o reforço de papéis de gênero tradicionais e a reiteração de uma suposta inferioridade feminina só contribuem para, por exemplo, manter condições favoráveis para a ocorrência da violência contra a 
mulher. É importante, então, que a escola trabalhe em prol de condições que favoreçam o desenvolvimento das/dos estudantes, e isso inclui um olhar crítico sobre os livros que estão sendo ali utilizados.

\subsection{LIVROS DIDÁTICOS: MUITO ALÉM DO SEU PAPEL}

Já é possível hoje em dia encontrar coleções de livros didáticos - entre elas diversas utilizadas na EJA - que trazem a mulher em seus textos e imagens, propiciando o debate sobre a presença dela nos ambientes de trabalho e como parte ativa da história. No entanto, percebe-se que não há uma consistência nisso, parecendo se tratar de uma imposição do mercado e/ou determinação governamental, e não uma inserção advinda da convicção pessoal das/os autoras/es. Deduz-se, então, que o livro didático não é neutro, desprovido de interesses - sejam ideológicos ou mercadológicos -, e que ele é marcado pelo momento histórico de sua publicação. Mais do que isso: ele é um importante veículo para a disseminação de certos sistemas de valores, ideologias, e mesmo de determinadas culturas, frequentemente transmitindo estereótipos e valores de grupos dominantes. Segundo Allan Choppin,

[...] a imagem da sociedade apresentada pelos livros didáticos corresponde a uma reconstrução que obedece a motivações diversas, segundo época e local, e possui como característica comum apresentar a sociedade mais do modo como aqueles que, em seu sentido amplo, conceberam o Livro Didático gostariam que ela fosse, do que como ela realmente é. (CHOPPIN, 2004, p.557).

Com a obrigação de reavaliarem o conteúdo de seus livros didáticos para se adequar às exigências do MEC, as editoras passaram a lançar materiais com as mais diversas abordagens, inclusive no que se refere a gênero. Entretanto, um grande número de livros didáticos - inclusive do PNLD - ainda hoje reforça papéis de gênero tradicionais e fala pouco da participação das mulheres nos processos históricos. Quando o fazem, é como se tal fato fosse uma curiosidade, algo fora do normal, e assim as conquistas e o sucesso das mulheres ficam marcados como uma exceção, como algo fora da realidade e "para poucas", perpetuando o assujeitamento feminino. 


\section{Atos de Pesquisa em Educação - ISSN 1809-0354 \\ Blumenau, v.14, n.2, supl.1, p.792-814, out./nov. 2019}

DOI: http://dx.doi.org/10.7867/1809-0354.2019v14n2s1p792-814

Por outro lado, não podemos esquecer que o livro didático é uma mercadoria que sofre interferências variadas em seu processo de fabricação. Assim, ainda que quem escreva o livro tenha a intenção de promover a igualdade de gênero na forma de apresentar a mulher, outras pessoas e fatores interferem na produção da obra ilustradores, programadores visuais, a editora responsável pela impressão, etc -, organizando uma forma de leitura que pode não ser a imaginada no momento de escrita do livro. Uma ilustração de um astronauta (homem), por exemplo, pode ser escolhida em detrimento da de uma astronauta (mulher) simplesmente por não ter que pagar direitos de reprodução ou porque seu número de pixels fará com que tenha melhor qualidade na impressão, ou seja, o livro didático é limitado e condicionado não apenas por razões ideológicas, mas também por questões econômicas e/ou técnicas.

Com isso, o papel do livro didático pode acabar sendo - ainda que não propositalmente - o de reproduzir ideologias e modos de pensar de determinados setores do poder, mas é exatamente o uso que docentes e estudantes irão fazer dele que pode subverter tal ordem. As práticas envolvidas no trabalho com o livro didático não obedecem necessariamente às regras impostas por autoras/es, editoras ou mesmo instituições governamentais, e mesmo que as imagens sejam diretivas, existem diferentes formas de abordá-las, especialmente se isso for feito com um olhar crítico, sendo a atuação da professora ou professor, então, fundamental.

\subsection{A ORIGEM DE NOSSO OBJETO DE ESTUDO: O PROGRAMA NACIONAL DO LIVRO DIDÁTICO PARA A EDUCAÇÃO DE JOVENS E ADULTOS (PNLD EJA)}

O PNLD tem por objetivo dotar as escolas públicas de ensino fundamental e médio de livros didáticos e outras publicações. O Programa ocorre em ciclos trienais alternados e, a cada ano, o Fundo Nacional de Desenvolvimento da Educação (FNDE) adquire e distribui livros para todos as/os estudantes de determinada etapa de ensino, repondo e complementando os livros reutilizáveis para outras etapas. Um edital especifica os critérios para inscrição das obras por parte das editoras, e os títulos inscritos são avaliados pelo Ministério de Educação e Cultura (MEC). Após a seleção, um Guia do 


\section{Atos de Pesquisa em Educação - ISSN 1809-0354 \\ Blumenau, v.14, n.2, supl.1, p.792-814, out./nov. 2019}

DOI: http://dx.doi.org/10.7867/1809-0354.2019v14n2s1p792-814

Livro Didático com as resenhas de cada obra aprovada é elaborado pelo MEC e disponibilizado pelo FNDE às escolas participantes. As/Os professoras/es escolhem então, dentre os livros constantes no Guia, aqueles que desejam utilizar, levando em consideração o planejamento pedagógico de cada escola. Em relação à EJA, o PNLD EJA distribui livros didáticos para jovens e adultos das entidades parceiras do Programa Brasil Alfabetizado (PBA) e das redes de ensino da educação básica (BRASIL, 2017a), sendo que a última edição ocorreu em 2014. (BRASIL, 2017b).

Os Guias mais recentes do PNLD trazem a preocupação com a questão das mulheres, e isso se verifica nas resenhas de algumas das coleções aprovadas, que deixam claro se elas contemplam a discussão sobre a atuação feminina na História ou se vão além, discutindo questões de gênero em geral. Por outro lado, vários livros do PNLD - inclusive alguns da EJA - ainda apresentam a mulher como ligada primariamente à esfera doméstica ou em ocupações relacionadas ao cuidado com outras pessoas (professora, enfermeira, médica); mostrando-a em outras esferas e exercendo profissões consideradas "masculinas" como casos excepcionais, naturalizando assim papéis de gênero historicamente determinados. Por isso, optamos por verificar como a mulher é representada nos livros da EJA especificados a seguir.

\subsection{ALCANCE EJA - ANOS FINAIS DO ENSINO FUNDAMENTAL}

Os dois livros selecionados para serem analisados se destinam aos Anos Finais do Ensino Fundamental (6ำ ao $9^{\circ}$ ano) e pertencem à coleção Alcance $E J A$, da Editora Positivo (Curitiba), publicada em 2013. O livro de Língua Portuguesa é de autoria de Ana Laura Volp, enquanto o de Língua Estrangeira Moderna - Inglês e Espanhol foi escrito por Joseandra Decimo Grazziottin e Alexandre dos Santos Batista (Inglês) e Maria Josele Bucco Coelho (Espanhol).

Segundo o Guia do PNLD EJA (BRASIL, 2014, p.193), os conteúdos são apresentados na coleção a partir de unidades temáticas, subdividas em capítulos e diversas seções. As unidades temáticas estão de acordo com a proposta curricular para a EJA, considerando os temas transversais e as especificidades de jovens e adultos. Em 
relação a imagens, segundo o Guia, "[o]s recursos iconográficos estão bem apresentados: fotos, reproduções de quadros, gráficos, mapas e esquemas são organizados em quantidade necessária e dialogam com os textos verbais" (BRASIL, 2014, p.194). Quanto aos exercícios, a avaliação é de que o Alcance EJA "contém atividades que propiciam experiências de aprendizagem significativas, diversificadas e contextualizadas, atendendo às características de aprendizagem dos estudantes da EJA". (BRASIL, 2014, p.194).

Em relação à mulher, o Guia diz que, ao tratar do mundo do trabalho, a obra destaca diversas profissões e discute a participação da mulher nessa esfera, sendo um dos "vários pontos dignos de destaque" o modo como são abordados temas atuais e relevantes para o público da EJA, tais como "imigração e identidade, mundo do trabalho e as profissões, a diversidade de gêneros e questões ambientais". (BRASIL, 2014, p.194). Já na seção Recomendações para uso em sala de aula, o Guia só retoma a menção a gênero e, mais especificamente, à mulher quando fala do eixo das Ciências, sobre o qual diz ser destaque "a importância dos temas transversais sobre pluralidade cultural e orientação sexual ali presentes", sendo discutida "a saúde das mulheres, tanto no campo quanto na cidade, em especial a saúde de mulheres na terceira idade" e propostas "questões que valorizam a diversidade de gênero e a idade". (BRASIL, 2014, p.202). Quando se trata dos volumes sobre Língua Portuguesa e Língua Estrangeira Moderna, nada é mencionado em relação à mulher.

Apesar de a resenha do Guia do PNLD EJA sobre a coleção Alcance EJA ser bastante positiva e inclusive elogiar a forma como ela aborda questões de gênero e a mulher, acreditamos haver pontos onde uma análise mais aprofundada de seus livros perceba que a presença de um tema como gênero e uma aparente valorização da mulher na obra apenas disfarçam a presença de pré-conceitos e preconceitos cristalizados, problema que queremos demonstrar com este trabalho.

\section{O QUE FIZEMOS}


 \\ Blumenau, v.14, n.2, supl.1, p.792-814, out./nov. 2019 \\ DOI: http://dx.doi.org/10.7867/1809-0354.2019v14n2s1p792-814}

Para a escolha dos livros que foram objeto deste estudo utilizamos os seguintes critérios: 1) livros que tivessem sido escolhidos pelo PNLD EJA no ano de 2013 - ou seja, do lote distribuído mais recentemente, em 2014 - e que tivessem sido selecionados para uso em nossa cidade; 2) livros da mesma área: Línguas - tanto a materna (Português) como as estrangeiras modernas (Inglês e Espanhol).

Quanto ao foco de observação nesses livros, optamos por centralizar nosso estudo na mulher, já que o espaço de um artigo não comportaria uma análise de gêneros em geral. Nesse sentido, consideramos a mulher como uma categoria historicamente construída por um sistema social normativo que distingue os seres humanos com base em seu sexo, impondo a homens e mulheres não só uma hierarquização, mas também obrigações, proibições e permissões. Sabemos também da interseccionalidade existente entre a categoria "mulher" e outras como raça, idade e classe social, mas apesar da importância dessas outras categorias, elas não foram incluídas em nosso estudo também por questões de espaço.

Escolhido nosso foco de observação, passamos à coleta das imagens nos livros. Além das capas, todas as páginas (de início de unidade ou com exercícios) em que foi utilizada uma imagem de mulher ou onde havia pessoas (e, portanto, a possibilidade de utilização da imagem de uma mulher ao invés de um homem) foram, então, digitalizadas. A partir daí, procedemos às análises descritiva e interpretativa das imagens, sendo que nessa última utilizamos como base o trabalho de Kress e Van Leewen (2006). É importante frisar que, a fim de tornar a leitura deste trabalho mais acessível, buscamos nos ater a aspectos das imagens que não necessitassem de conhecimentos aprofundados sobre essa teoria para entendimento de nossa análise. No intuito de organizar o que observamos, as imagens que elegemos para apresentar como, em livros didáticos, podem estar escondidos estereótipos, pré-conceitos e preconceitos em relação à mulher foram divididas em três grupos de acordo com a parte do livro onde elas se encontram, observações essas que apresentamos a seguir.

\section{O QUE DESCOBRIMOS}


DOI: http://dx.doi.org/10.7867/1809-0354.2019v14n2s1p792-814

\subsection{NAS CAPAS DOS LIVROS}

Figuras 1 e 2 - Capas dos livros de Língua Portuguesa e de Língua Estrangeira Moderna - Inglês e Espanhol
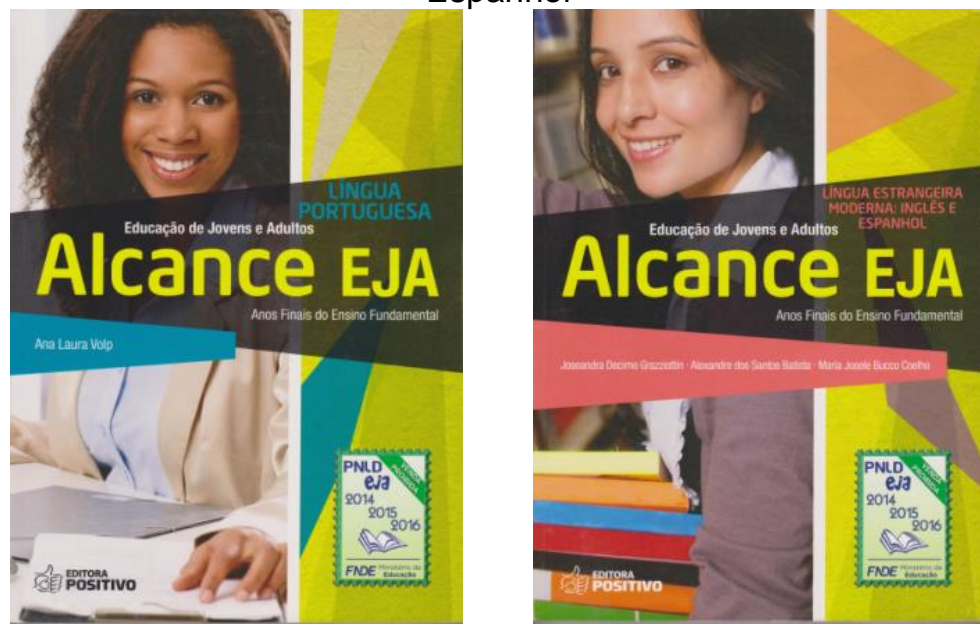

Fonte: VOLP, 2013 e GRAZIOTTIN; BATISTA; COELHO, 2013.

Capas de livros didáticos são o primeiro contato que a/o estudante tem com o material, e elas podem refletir tanto a real ideologia presente no livro como ser apenas um disfarce para ela, fazendo-o parecer democrático e de vanguarda quando na verdade é um perpetuador de modos de pensar conservadores e/ou preconceituosos.

A imagem na capa do livro de Língua Portuguesa (Figura 1) é de uma mulher jovem, negra, que está em um ambiente aparentemente de trabalho. A do livro de Língua Estrangeira Moderna (Figura 2) também é de uma mulher jovem, porém branca, e ela carrega livros ou cadernos, sugerindo um ambiente acadêmico. O uso dessas fotos nas capas coloca a mulher em posição de evidência, sugerindo ser essa a postura adotada nos livros, e o olhar das duas moças diretamente para a câmera estabelece um contato direto com quem observa as imagens, criando o que Kress e VanLeewen (2006, p.117) chamam de "exigência" (a pessoa retratada "exige" algo de quem a observa). Em outras palavras, as mulheres das fotos estão visíveis e atuantes.

Por outro lado, apesar de nenhuma delas estar em um ambiente doméstico, não fica claro se são uma secretária ou uma executiva/empresária (livro de Língua

\footnotetext{
${ }^{2}$ Todas as citações dessa obra serão de tradução nossa.
} 
Portuguesa), uma professora ou uma estudante (livro de Língua Estrangeira Moderna). Dessa forma, podemos ter uma reiteração de ocupações "femininas" (secretária, professora) ou uma valorização da mulher com ocupações que the dão mais poder (executiva/empresária, estudante), dependendo de como a pessoa que observa as imagens as interpreta. Com isso, se por um lado é evidente a intenção de dar visibilidade à mulher, por outro, quando se observa a ocupação em que ela é retratada, fica a dúvida se ela está sendo mantida em papéis de gênero tradicionais ou sendo empoderada. Essa ambiguidade que faz com que as imagens possam ser interpretadas de diferentes maneiras é de certa forma perigosa, pois nem sempre a leitura feita é em prol da mulher.

\subsection{NAS PÁGINAS DE INÍCIO DAS UNIDADES}

Em diversas coleções de livros didáticos os volumes são divididos em unidades, e essas muitas vezes são introduzidas por uma página - ou no mínimo uma imagem - que apresenta e/ou ilustra o conteúdo que será abordado ali. As imagens no início de unidades podem, porém, refletir muito mais do que o conteúdo a ser estudado e delatar como o livro realmente encara a questão de gênero - em nosso caso, mais especificamente, a mulher.

Figuras 3 e 4: Início de unidades dos livros de Língua Portuguesa (p.51) e de Língua Estrangeira Moderna - Inglês (p.8) 
Atos de Pesquisa em Educação - ISSN 1809-0354

Blumenau, v.14, n.2, supl.1, p.792-814, out./nov. 2019

DOI: http://dx.doi.org/10.7867/1809-0354.2019v14n2s1p792-814
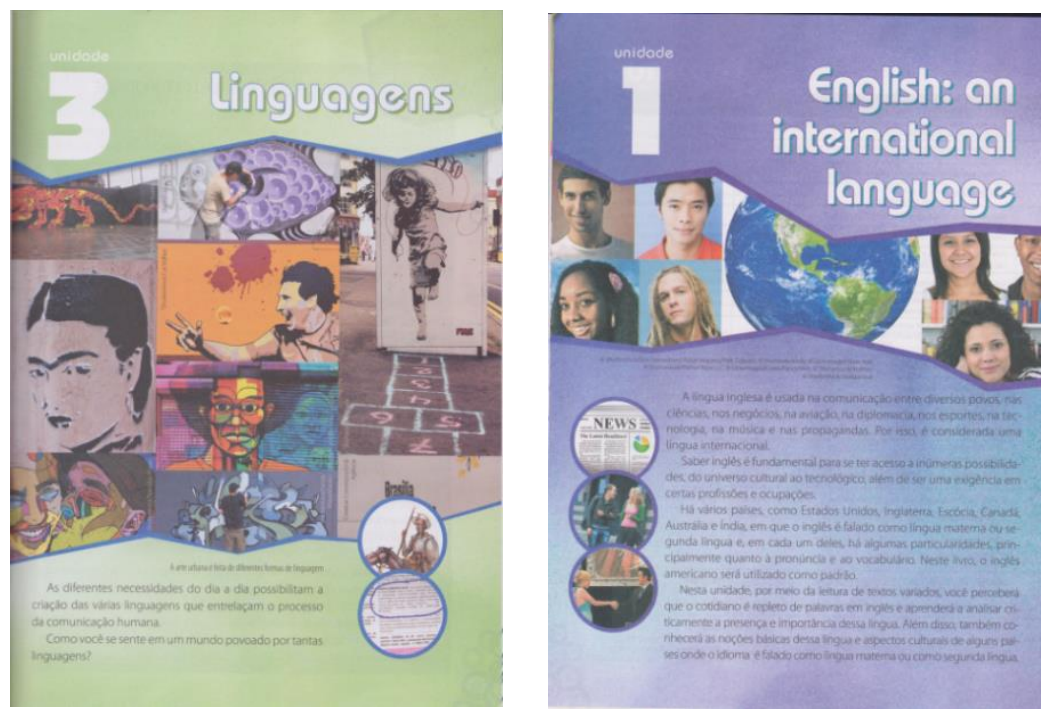

Fonte: VOLP, 2013 e GRAZIOTTIN; BATISTA; COELHO, 2013.

Figura 5: Início de unidade do livro de Língua Estrangeira Moderna - Espanhol (p.134-135)

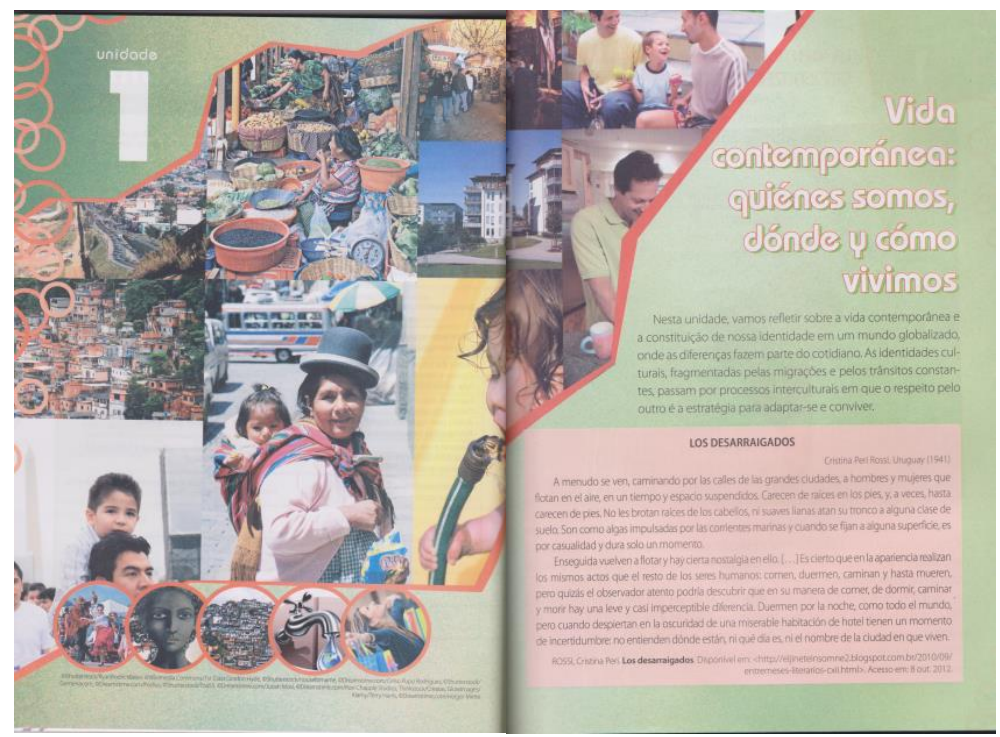

Fonte: GRAZIOTTIN; BATISTA; COELHO, 2013.

O padrão adotado para o início das unidades nos dois livros analisados é igual para ambos: um mosaico de imagens (em sua maioria fotos) que representam ou têm relação com o tema abordado naquela unidade. As fotos são tanto de pessoas como de locais e objetos, mas pode-se observar que, nas páginas em que há a presença de pessoas, o que se vê na grande maioria das vezes são fotos de homens. Em alguns 
casos, porém, é possível ver que há a intenção de incluir a figura feminina, como no início da Unidade 3, do livro de Língua Portuguesa (Figura 3), e das Unidades 1 de Inglês e de Espanhol (Figura 4 e 5). Quando as imagens são observadas com mais cuidado, entretanto, surgem algumas questões.

No caso do livro de Língua Portuguesa, por se tratar de uma unidade sobre "Linguagens", com exceção de uma imagem de Dom Quixote remetendo a um dos textos que serão trabalhados posteriormente, as outras são de obras de graffiti, sendo duas delas fotos de pinturas sendo executadas. São nove obras de graffiti e, dessas, cinco retratam pessoas, porém dentre as cinco, apenas uma retrata uma figura feminina facilmente identificável como tal e reconhecível: Frida Kahlo. O fato de ela, ícone do feminismo, ter sido escolhida e de sua imagem ser a maior da página merece destaque, porém, comparada com a posição central - que não só atrai o olhar de quem observa a imagem, mas também indica que ali está "o núcleo da informação à qual todos os outros elementos são subservientes" (KRESS; VAN LEEWEN, 2016, p.196) - do grafitti, representando o ídolo e jogador de futebol Zico, a localização da de Frida Kahlo a coloca em uma posição menos importante que a de um homem. Além disso, a imagem de Zico é colorida e em uma tonalidade "quente", chamativa, enquanto a de Kahlo é em preto e branco, ou seja, mais discreta e menos atrativa. (KRESS; VAN LEEWEN, 2006, p.235). Com isso, pode-se dizer que há um embate na leitura, uma disputa da atenção de quem observa a página, sendo a imagem feminina desfavorecida.

Outras duas imagens dentre as nove que apresentam pessoas podem ser de mulheres, mas não há como se ter certeza disso. À direita, por exemplo, há um painel com o graffiti, em tons de preto, branco e cinza, de uma criança que parece ser uma menina pulando amarelinha, mas poderia perfeitamente ser um menino de cabelos longos. Já à esquerda, na parte inferior, há a figura de um homem beijando outra pessoa, a qual tanto pode ser uma mulher como outro homem. Com essa ambiguidade, a certeza de que a mulher está presente nas imagens resume-se à de Frida Kahlo. Nas outras três imagens de graffiti com pessoas, quem aparece são homens: o do beijo, Zico, e um homem da raça negra, retratado em cores fortes e vibrantes logo abaixo do jogador. 


\section{Atos de Pesquisa em Educação - ISSN 1809-0354 \\ Blumenau, v.14, n.2, supl.1, p.792-814, out./nov. 2019}

DOI: http://dx.doi.org/10.7867/1809-0354.2019v14n2s1p792-814

Nessa obra retratando o homem negro, é interessante verificar que no plano de fundo pode-se vislumbrar mais três pessoas: uma mulher, outro homem e uma pessoa de gênero não identificável, todas apenas delineadas. Das três, a mais perceptível é a mulher, mas ainda assim ela é uma forma quase etérea, e, como já dissemos, está atrás do homem, demonstrando ter sido dada preferência e destaque à figura masculina afinal, poderia ser a imagem de uma mulher negra ao invés de um homem em primeiro plano e, mesmo estando em segundo plano, a imagem da mulher poderia estar mais nítida, ao invés de quase invisível. É claro que, ao falar da nitidez da representação, não estamos questionando a opção técnico-artística de quem fez o graffiti, mas sim a repercussão resultante de uma das possíveis leituras da obra: a posição subordinada e quase invisível da mulher.

Por fim, há ainda duas fotos de artistas executando obras de graffiti, porém ambos são homens. A opção por fotos de artistas do sexo masculino é passível de questionamento, pois há mulheres famosas nessa modalidade de arte no Brasil, sendo que o trabalho delas - principalmente o ligado a coletivos feministas - é reconhecido internacionalmente. (PABÓN, 2016). Além disso, em conjunto com a imagem de Zico e a do homem negro, as fotos dos dois artistas cria uma linha vertical formada totalmente por homens, linha essa em que "o que está localizado no topo é apresentado como Ideal e o que está na parte de baixo é mostrado como o Real". (KRESS; VAN LEEWEN, 2016, p.186-187). Em outras palavras, é possível uma leitura na qual desde o que é considerado "ideal" até o visto como "real", tudo e todos são homens. É claro que há a possibilidade de que tenha sido "mais fácil para a editora encontrar fotos de artistas homens do que mulheres grafitando nas ruas", mas considerando o conjunto de todas as imagens da página e as imagens do início de outras unidades do livro de Língua Portuguesa, configura-se um padrão de favorecimento da figura masculina em detrimento da feminina.

O livro de Línguas Estrangeiras Modernas, por sua vez, apresenta situações diferentes, dependendo da língua em questão. A parte dedicada ao Inglês mostra um quase equilíbrio no número de imagens de homens e mulheres no início das unidades, como no caso da sua Unidade 1 (Figura 4). Apesar de neste exemplo haver mais 
mulheres, no conjunto de todos os inícios de unidade há uma leve prevalência de imagens de homens, mas percebe-se uma clara intenção de incluir as mulheres e de apresentá-las em igualdade - seja no tamanho, seja na posição e/ou distribuição das imagens. Isso talvez se explique pelo fato de na Língua Inglesa há muito tempo haver uma preocupação com as questões de gênero. Atualmente, por exemplo, já é de praxe o uso de termos não designativos de gênero (como no caso de algumas profissões) a fim de eliminar quaisquer diferenciações e demonstrar igualdade.

Por outro lado, na parte dedicada ao Espanhol, percebe-se que o tratamento dado à mulher é diferente. Nas páginas de início de sua Unidade 1 (Figura 5) podem ser observadas onze pessoas adultas: cinco homens e seis mulheres. Ainda que estejam em número levemente superior e três delas (provavelmente peruanas a julgar pelas roupas e feições) nas maiores fotos, uma aparece no papel de mãe, carregando a filha nas costas, e duas vendendo produtos no mercado - sendo que, no Peru, o trabalho da mulher é apenas mais uma forma de cumprimento do trabalho doméstico. (CASTILLA, 1991). As outras três mulheres, todas nas fotos menores, são uma mulher negra, retratada em um graffiti com uma expressão de tristeza, e duas mulheres brancas dançando alegremente. Com isso, mesmo que lhes seja dado destaque com o tamanho de algumas fotos e em duas delas elas estejam aparentemente fazendo algo que lhes dá prazer (dançando), as mulheres aparecem, em sua maioria, cumprindo o papel "esperado" delas, quer dizer, em ocupações ligadas ao doméstico ou "sendo graciosas". Essa forma de retratar a mulher pode novamente ter relação com a língua, pois os países falantes de Espanhol da América Latina têm tradicionalmente uma cultura patriarcal, machista, e isso parece se refletir na escolha das imagens que ilustram os inícios de unidade, já que a única outra página desse tipo que apresenta fotos de seres humanos traz apenas homens.

Merece menção, entretanto, que dos cinco homens adultos que se vê na Figura 5, dois compõem um casal homoafetivo, outro está carregando o filho nos ombros, outro parece estar trabalhando na cozinha e outro está dançando com uma das mulheres mencionadas, ou seja, praticamente todos fogem do "esperado" de um homem. No entanto, como já dito, só há mais um início de unidade com imagens de pessoas no livro 


\section{Atos de Pesquisa em Educação - ISSN 1809-0354 \\ Blumenau, v.14, n.2, supl.1, p.792-814, out./nov. 2019}

DOI: http://dx.doi.org/10.7867/1809-0354.2019v14n2s1p792-814

de Espanhol, e ele traz homens em tradicionais papéis masculinos - sendo corajosos em esportes radicais e demonstrando inteligência ao lidar com a tecnologia -, indicando uma tendência à perpetuação da ideia da superioridade masculina.

Em resumo, assim como pode acontecer em vários outros livros, as páginas de início de unidade dos dois livros do Alcance EJA que observamos tentam passar uma ideia de apoio à mulher na sua luta por igualdade de direitos e de representatividade, porém o que se vê, na verdade, é que a superioridade masculina ainda está fortemente presente, seja em termos de como os homens são apresentados, seja em frequência de aparição.

\subsection{NAS ILUSTRAÇÕES DE TEXTOS, EXPLICAÇÕES, EXEMPLOS E EXERCÍCIOS}

As gravuras, ilustrações e fotos que acompanham textos, explicações e exemplos em livros didáticos têm a função de auxiliar na compreensão e facilitar a memorização de conteúdos, enquanto as utilizadas em exercícios são muitas vezes parte essencial para a realização deles. No caso de livros de línguas, um texto literário frequentemente encontra apoio nas imagens para ser lido, sendo que quando se trata de línguas estrangeiras, elas ainda se tornam ferramenta de extrema importância para apresentação e consolidação de vocabulário. Nesse processo, porém, pode ocorrer um "direcionamento", pois há a chance de as imagens influenciarem o modo de pensar da pessoa que as observa a respeito daquele tema, dependendo do que é escolhido para ilustrar o quê - já que, como dissemos, essa escolha pode não ser apenas de origem técnica nem econômica, mas sim ideológica.

Vejamos o que ocorre, por exemplo, com a imagem que ilustra um texto de Leon Eliachar sobre anúncios publicitários na TV no livro de Língua Portuguesa (Figura 6). Em dado momento, o texto fala de propagandas de refrigerantes e, logo acima, aparece a foto de uma TV antiga com uma pirâmide de latas de refrigerante sobre ela. Na tela da TV há uma ilustração estilo vintage mostrando um homem sorridente (em cores) segurando uma lata de refrigerante em primeiro plano, e, atrás dele, o rosto de uma mulher, de outro homem e um pedaço de uma pessoa de gênero não discernível, todos 
em desenho linear e sorrindo. Novamente surge a questão sobre o porquê da preferência pela imagem de um homem, se até anúncios de refrigerante originais da mesma época dessa ilustração apresentavam mulheres.

Já no caso das imagens utilizadas como exemplo do conteúdo sendo estudado, podemos verificar a preferência por e a predominância de fotos de homens no livro de Inglês (Figura 7). Ali o problema da representação é mais preocupante, pois as imagens retratam profissões e, em doze fotos, temos apenas três mulheres, as quais ilustram as ocupações de professora, atendente de loja e empregada doméstica. Os homens, nas outras nove fotos, são um estudante, um fazendeiro, um carpinteiro, um bombeiro, um mecânico, um padeiro e um eletricista, além de Antônio Fagundes e Caetano Veloso ilustrando as profissões de ator e cantor. Verifica-se, portanto, uma preferência por fotos de homens, já que há atrizes e cantoras tão famosas quanto as duas celebridades masculinas das fotos, sem falar que certamente existem mulheres estudantes, fazendeiras, bombeiras, mecânicas e eletricistas. Esse reforço de papéis tradicionais de gênero nega às mulheres a chance de se verem retratadas em profissões que não as "destinadas" a elas, perpetuando para as estudantes da EJA a ideia de que o lugar delas é em casa e/ou cuidando dos outros. Considerando que a Unidade 7 do livro de Inglês trata justamente sobre o mercado de trabalho e a mulher - trazendo inclusive o problema da divisão de trabalho baseada no gênero em um texto -, a predominância de fotos de homens e a forma como as mulheres aparecem retratadas fora dessa unidade indicam que o tema provavelmente está presente apenas por uma exigência do MEC.

Por fim, também nas imagens utilizadas em exercícios verifica-se o uso de fotos de homens que poderiam perfeitamente ser substituídas por fotos de mulheres - ou pelo menos também incluir mulheres. É o caso do livro de Espanhol (Figura 8), no qual em um exercício em que a pessoa tem de associar o nome do esporte radical à foto dele, todas as fotos retratam homens. Com isso, perpetua-se a falsa ideia de que as mulheres não têm condições de ou não estão autorizadas a praticar esses esportes, que a coragem é um atributo masculino, e que o sucesso em situações difíceis pertence aos homens concepções que em nada auxiliam as estudantes da EJA. 
Atos de Pesquisa em Educação - ISSN 1809-0354

Blumenau, v.14, n.2, supl.1, p.792-814, out./nov. 2019

DOI: http://dx.doi.org/10.7867/1809-0354.2019v14n2s1p792-814

Figuras 6 e 7 - Ilustração de texto (Língua Portuguesa, p.57) e de exemplo de conteúdo (Língua Estrangeira Moderna - Inglês, p.34-35)
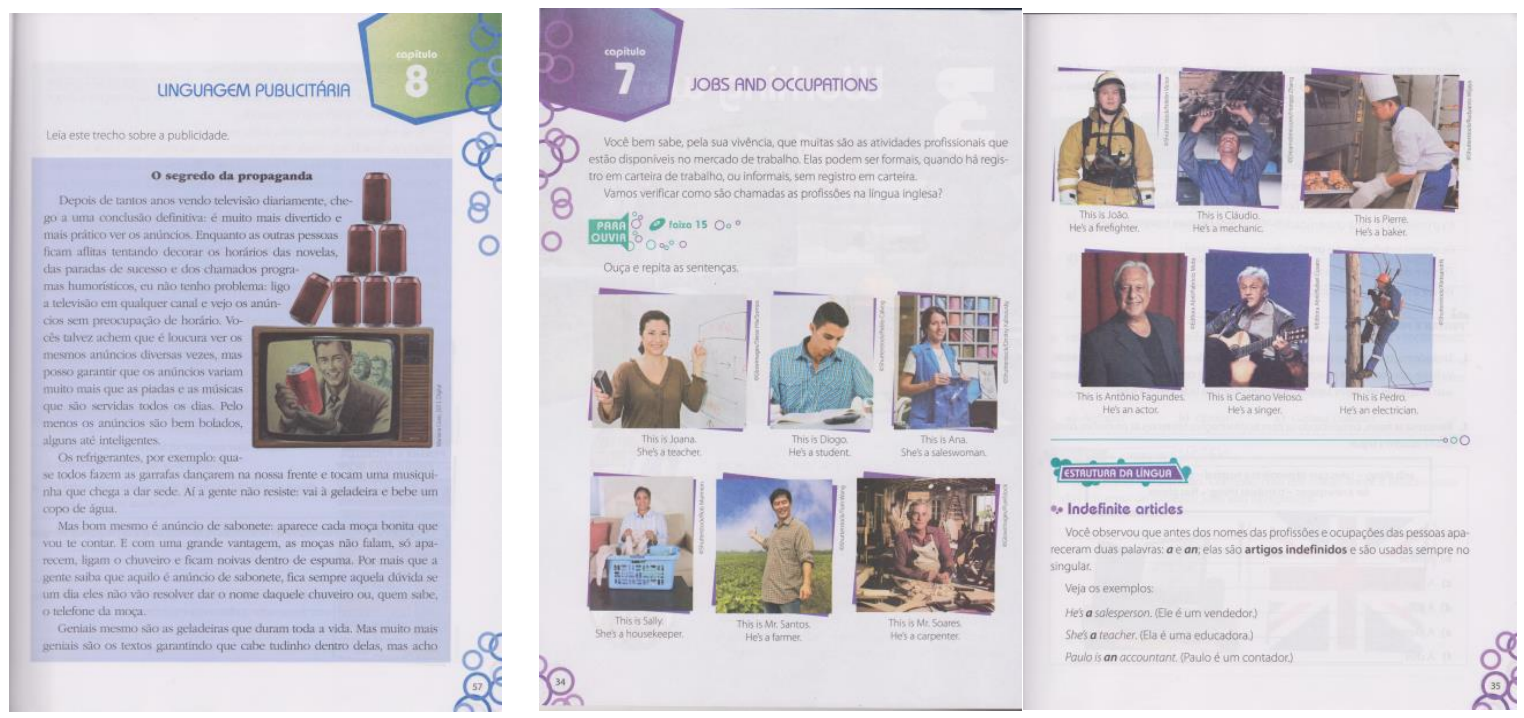

Fonte: VOLP, 2013 e GRAZIOTTIN; BATISTA; COELHO, 2013.

Figura 8: llustração de exercício (Língua Estrangeira Moderna - Espanhol, p.8)

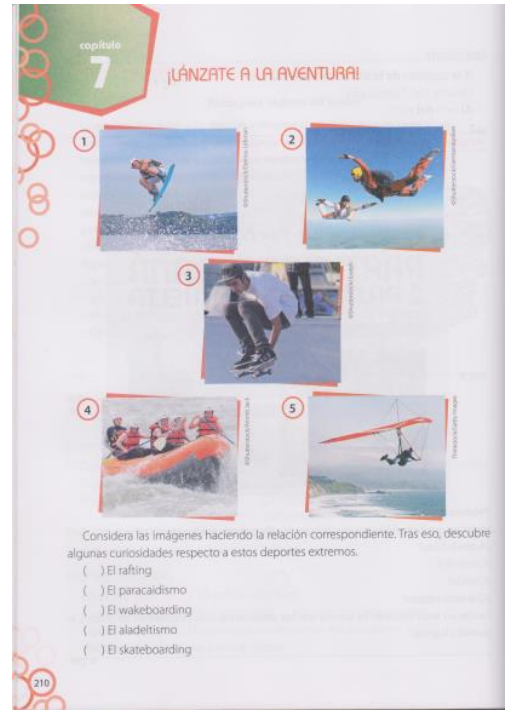

Fonte: GRAZIOTTIN; BATISTA; COELHO, 2013.

Os casos descritos aqui demonstram aquilo que pode ser verificado de forma geral nos livros analisados, ou seja, que apesar de aparentemente os livros se preocuparem em trazer à luz e à discussão as questões relativas à mulher, na verdade as imagens que 
Atos de Pesquisa em Educação - ISSN 1809-0354

Blumenau, v.14, n.2, supl.1, p.792-814, out./nov. 2019

DOI: http://dx.doi.org/10.7867/1809-0354.2019v14n2s1p792-814

os ilustram contam outra história, a da preponderância do masculino e a visão da mulher como subordinada ao homem ainda continuam sendo perpetuadas.

\section{CONSIDERAÇÕES FINAIS: PARA MANTER A DISCUSSÃO VIVA}

Antes de encerrarmos nossas considerações sobre o que verificamos nas imagens dos livros analisados, cabe salientar que optamos por não incluir entre elas as unidades 15 (“Novos papéis sociais") do livro de Língua Portuguesa e 7 ("Labor Market") da parte de Inglês do livro de Língua Estrangeira Moderna, ambas dedicadas às mulheres, já que ali, obviamente, as imagens de mulheres seriam no mínimo predominantes em número em relação às de homens. Ao mesmo tempo, apesar da existência de unidades específicas sobre as mulheres, ao observarmos os livros como um todo verificamos que não há efetivamente uma mudança na representação delas nas imagens utilizadas. Quanto à representatividade, é óbvio que não queremos que os livros tenham apenas imagens de mulheres ou mesmo que a maioria das imagens seja de mulheres, mas sim que haja um equilíbrio na distribuição entre homens e mulheres, e não o predomínio de imagens de homens como foi verificado. Fica claro então que, como já salientamos, as unidades dedicadas à mulher estão presentes apenas devido às exigências do MEC sobre os temas que os livros do PNLD devem abordar, e não por uma conviç̧ão da necessidade de mudar o modo como a mulher é apresentada e representada em livros didáticos, o que muito nos preocupa.

Todos esses pontos que observamos nos livros reafirmam nossa crença de que crianças, assim como jovens e adultos - sejam da EJA ou do ensino regular - que fazem uso de livros didáticos, necessitam que as/os professoras/es trabalhem em sala de aula com um olhar crítico sobre essas publicações, questionando não apenas as imagens como demonstrado aqui, mas também os textos e frases de exemplo escolhidos, dando

oportunidade às/aos alunas/os de construírem suas identidades sem a imposição de modelos de gênero. Esperamos que este trabalho contribua, ainda que minimamente, para auxiliar as/os docentes nisso, e que ajude a escola a cumprir com sua maior missão, a de auxiliar as pessoas a se tornarem seres humanos plenos e realizados. 


\section{RENATA KABKE PINHEIRO}

Licenciada em Inglês e Respectivas Literaturas (2004), Mestre em Letras (2007) e Doutora em Linguística Aplicada - Área de Texto, Discurso e Relações Sociais (2011) pela Universidade Católica de Pelotas (UCPel). É Professora Adjunta do curso de Licenciatura em Letras Português-Inglês da Universidade Federal de Pelotas (UFPel).

\section{MÁRCIA ALVES DA SILVA}

Bacharel em Ciências Sociais (1996) e Mestre em Educação (2002) pela Universidade Federal de Pelotas (UFPel). Doutora em Educação (2010) pela Universidade Vale do Rio dos Sinos (UNISINOS). É Professora Adjunta e atua no Programa de Pós-Graduação em Educação da Faculdade de Educação da Universidade Federal de Pelotas (UFPel).

\section{REFERÊNCIAS}

BAKTHIN, M.M. (Volochínov). Marxismo e filosofia da linguagem. São Paulo: Hucitec, 1988.

BRASIL. Ministério da Educação. Secretaria de Educação Continuada, Diversidade e Inclusão. Guia dos Livros Didáticos do PNLD EJA 2014. Natal: EDUFRN, 2014.

BRASIL. Fundo Nacional de Desenvolvimento da Educação. Programas do livro Apresentação. Disponível em: <http://www.fnde.gov.br/programas/programas-dolivro/legislacao/item/619apresenta\%C3\%A7\%C3\%A3o?highlight=WyJlamEiLCJlc2NvbG hhll0=>. Acesso em: 15 jul. $2017 a$.

BRASIL. Ministério da Educação. Programa Nacional do Livro Didático para Educação de Jovens e Adultos - PNDL EJA - Calendário de Atendimento. Disponível em: $<$ http://portal.mec.gov.br/index.php?option=com_content\&view=article \&id=17458>. Acesso em: 15 jul. 2017b.

BUTLER, J. Problemas de gênero: feminismo e subversão da identidade. Rio de Janeiro: Civilização Brasileira, 2003.

CASTILLA, N. A. Mujer, sociedade e crisis en el Perú. INTERCAMPUS Población: presente e futuro del Perú. Lima: Centro de Investigación de la Universidad del Pacífico, 1991. p. 23-92.

CHOPPIN, A. História dos Livros e das edições didáticas: sobre o estado da arte. Educação e Pesquisa. São Paulo, v.30, n. 3, p. 549-566, set/dez. 2004. 


\section{Atos de Pesquisa em Educação - ISSN 1809-0354}

DOI: http://dx.doi.org/10.7867/1809-0354.2019v14n2s1p792-814

FLAX, J. Pós-modernismo e as relações de gênero na teoria feminista. In: HOLLANDA, Heloísa Buarque de (org.). Pós-modernismo e política. Rio de Janeiro: Rocco, 1991. p. 217- 250.

GRAZZIOTTIN, J. D.; BATISTA, A. S.; COELHO, M. J. B. Educação de Jovens e Adultos: Alcance EJA: língua estrangeira moderna: inglês e espanhol: anos finais do Ensino Fundamental. Curitiba: Positivo, 2013.

HOOKS, B. Ensinando a transgredir: a Educação como prática de liberdade. São Paulo: Martins Fontes, 2013.

KRESS, G. R.; VAN LEEUWEN, T. Reading images: the grammar of visual design. New York: Routledge, 2006.

PABÓN, J. N. Ways of being seen: gender and the writing on the wall. In: ROSS, J. I. (ed.). Routledge Handbook of Graffiti and Street Art. New York: Routledge, 2016. p. 7892.

PELLEGRINI, T. Despropósitos: estudos de ficção brasileira contemporânea. São Paulo: Annablume, 2008.

SCOTT, J. Gênero: uma categoria útil de análise histórica. Educação e Realidade. Porto Alegre, v. 20, n. 2, p. 71-99, jul./dez., 1995.

VOLP, A. L.. Educação de Jovens e Adultos: Alcance EJA: língua portuguesa: anos finais do Ensino Fundamental. Curitiba: Positivo, 2013.

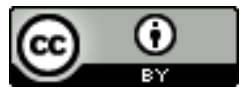

Esta obra está licenciada com uma Licença Creative Commons Atribuição 4.0 Internacional 